\title{
Cervical Spine Cord Injury Associated with Klippel-Feil Syndrome: A Case Report
}

\author{
Roger Mulumba Ilunga ${ }^{1}$, Mohameth Faye ${ }^{1}$, Abdoulaye Diop ${ }^{2}$, \\ Nicaise Akodjetin Mahougnon Sodjinou' ${ }^{1}$, Vital Nacoulma ${ }^{1}$ \\ ${ }^{1}$ Department of Neurosurgery, Regional Hospital Center of Thiès, Thiès, Senegal \\ ${ }^{2}$ Department of Neurosurgery, Regional Hospital of Ziguinchor, Ziguinchor, Senegal \\ Email: *rogermulumba2004@gmail.com
}

How to cite this paper: Ilunga, R.M., Faye, M., Diop, A., Sodjinou, N.A.M. and Nacoulma, V. (2021) Cervical Spine Cord Injury Associated with Klippel-Feil Syndrome: A Case Report. Open Journal of Orthopedics, 11, 138-145.

https://doi.org/10.4236/ojo.2021.114013

Received: February 16, 2021

Accepted: April 18, 2021

Published: April 21, 2021

Copyright $\odot 2021$ by author(s) and Scientific Research Publishing Inc. This work is licensed under the Creative Commons Attribution International License (CC BY 4.0).

http://creativecommons.org/licenses/by/4.0/

\begin{abstract}
Background: Klippel Feil syndrome (KFS) is a congenital malformation characterised by the presence of, at least, one fused cervical segment and results from faulty segmentation along the embryo's developing axis during weeks 3 - 8 of gestation. The KFS increases the risk for spinal cord injury after minor trauma as a result of the disturbance of the biomechanics of the cervical spine. Persons with KFS often have associated congenital anomalies. Aim: The purpose of this study was to show the surgical management difficulties of this pathology in a low income country such as Senegal and to make a review of the literature. Case presentation: A 32-year-old man developed a tetraparesis secondary to a fall from his height while carrying a bag of rice on his head. Radiological explorations revealed fusedC2-C3 and C4-C5 vertebral bodies with a C3-C4 disc herniation associated to a spine contusion. The patient underwent surgical removal of the herniated disc via an anterior approach followed by interbody fusion and anterior plating. A complete recovery was noted at 4 months follow-up. Conclusion: Understanding of the cervical spine biomechanics of Klippel-Feil anomaly may allow an optimal management of patients. Patients with KFS should be warned of the increased risk of spinal cord injury after a low velocity trauma. Timing for surgery should be shortened.
\end{abstract}

\section{Keywords}

Klippel-Feil, Spinal Cord Injury, Cervical Disc Herniation

\section{Background}

Klippel Feil syndrome (KFS) is a congenital malformation characterised by the presence of, at least, one fused cervical segment. The first case was reported in 
1912 by Maurice Klippel and André Feil [1]. In Senegal, 2 cases had been reported in the literature by AA Diop [2] and A Ly-Ba [3]. This congenital disorder affects anywhere from 1 in 40,000 to 50,000 live births [4] [5]. The etiology of KFS and its associated conditions is unknown. Gunderson et al. [6] suggested that KFS is a genetic condition, whereas Gray et al. [7] found a low incidence of inheritance. Its pathogenesis is thought to be the result of an anomaly in axial segmentation between the third and eighth week of embryonic development [8]. KFS is a complex syndrome of osseous and visceral anomalies. Less than $50 \%$ of KFS patients have the classic triad of short neck, limitation in head and neck movements and low posterior hairline [9]. The major feature of KFS is congenital fusion of two or more cervical vertebrae. This causes a biomechanical disturbance that increases the risk of developing neurological damage even in the event of minimal trauma to the cervical spine [10] [11]. Treatment approaches for KFS have been debated in the literature and they take into consideration individual patient factors. Here we present a case of a post-traumatic tetraparesis in a 32-years-old patient with KFS treated surgically with an anterior cervical discectomy and fusion. The difficulties encountered during the management of this case are discussed.

\section{Case Presentation}

A 32-years-old man, with no clinical history, was referred from a General Hospital, in Senegal, for a cervical spine trauma related to a domestic accident. He slipped and fell from his height while carrying a $50 \mathrm{Kg}$ bag of rice on his head. The patient was admitted in our Department, at the Regional Hospital Center of Thiès in Senegal, at day 3. He reported a cervical pain and numbness in all four limbs. On the initial examination, his vital signs were normal, the Glasgow Coma Scale score was 15 . The sensation was normal and the muscle strength in all limbs was 3/5. Bladder and bowel function were normal and an exaggeration of tendon jerks was noted in all limbs.

The cervical spine $\mathrm{X}$-ray from the Hospital of origin revealed a fusion of cervical segments at C2-C3 and C4-C5 levels, which were confirmed by a computerized tomography(CT) done in our hospital 3 days after admission. The cervical spine Magnetic Resonance Imaging (MRI), realised 8 days after admission, showed the two level fusions and a C3-C4 disc herniation with a spinal cord contusion at the same level (Figure 1). The patient was not assessed for potential associated abnormalities.

Surgery was performed 19 days after the initial injury. The patient underwent surgical treatment with an anterior cervical discectomy and fusion at the C3-C4 level. Under general anesthesia, the patient was positioned supine with slight extension of the neck on a non X-ray transparent operating table. Through a left anterior cervical approach, the C3-C4 level was exposed and confirmed with intraoperative fluoroscopic imaging. The longus coli muscles were mobilized and a self-retracting system was placed underneath them. The discectomy was done under direct vision without an operative microscope. A 11 blade was used 


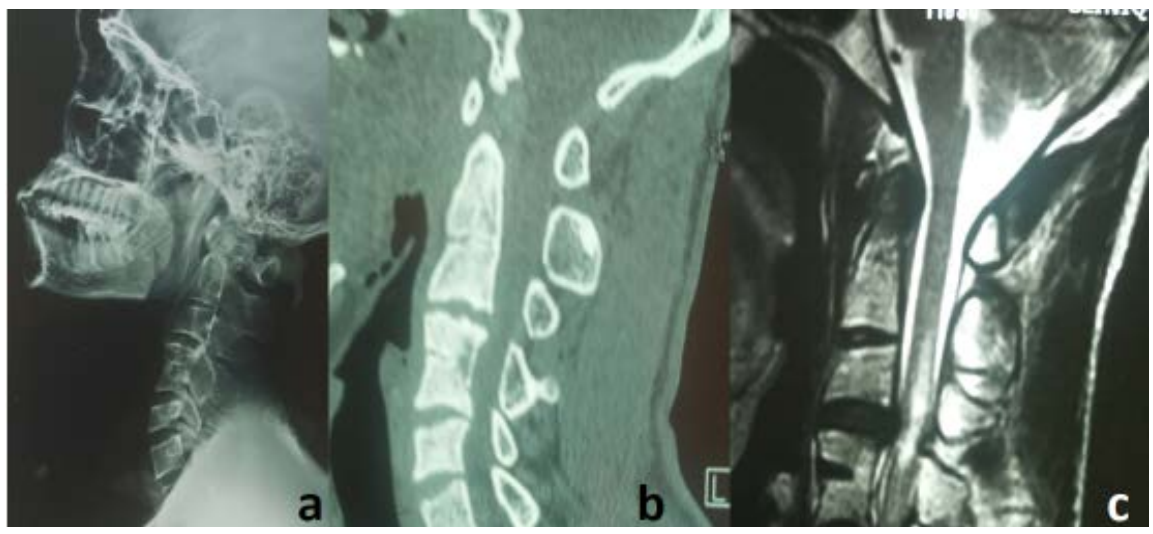

Figure 1. Lateral x-ray of cervical spine (a) and Computed Tomography (b) showing $\mathrm{C} 2-\mathrm{C} 3$ and $\mathrm{C} 4-\mathrm{C} 5$ vertebral body fusion. T2-weighted magnetic resonance image showing a $\mathrm{C} 3-\mathrm{C} 4$ disc prolapse resulting in compression of the dural tube and hyperintensity in the adjoining spinal cord (c).

to incise the disc space, and the disc material was removed using pituitary forceps. The discectomy was completed after applying a distraction with Caspar pins placed in the $\mathrm{C} 3$ and $\mathrm{C} 4$ vertebral bodies on the midline. The superior $\mathrm{C} 4$ and inferior $\mathrm{C} 3$ cartilaginous endplates were removed with curettes. The posterior common vertebral ligament was cut open to ensure that there was no transligamentous fragment. This procedure was followed by a C3-C4 interbody fusion with an autologous iliac crest bone graft. An anterior plate was positioned and drilled into place with screws under intraoperative lateral fluoroscopic imaging. The operating site was then irrigated with $0.9 \%$ saline solution and a drain was placed and secured with a suture. The platysma, the dermis and the epidermis were closed separatelly. A hard collar was placed for cervical immobilization. On day 1 after surgery the drain was removed and the postoperative X-ray was satisfactory (Figure 2). The postoperative course was uneventfull and the patient was discharged 4 days after surgery with a hard collar for 8 weeks. At 1 month follow-up, the muscle power had slightly improved with functional rehabilitation and muscle strengthening and we noted a full recovery at 4 months follow-up. We lost sight of the patient and he was seen 10 months after surgery. On examination, he was neurologically intact and the X-ray showed evidence of body fusion.

\section{Discussion}

Klippel-Feil syndrome is a rare disorder characterized by the congenital fusion of cervical vertebrae. The incidence of KFS has been estimated to be from 1 in 40,000 to 50,000 live births [4] [5] [12]. J. Gruber et al. [13] reviewed 2917 cervical CT scans from the emergency department of a level I trauma center in New York State over a one-year period and found a prevalence of 1 in 172, which is much higher than in previously described series. Clinical diagnosis may not be reliable, it is likely that this condition is underreported and may only be found incidentally on imaging. 


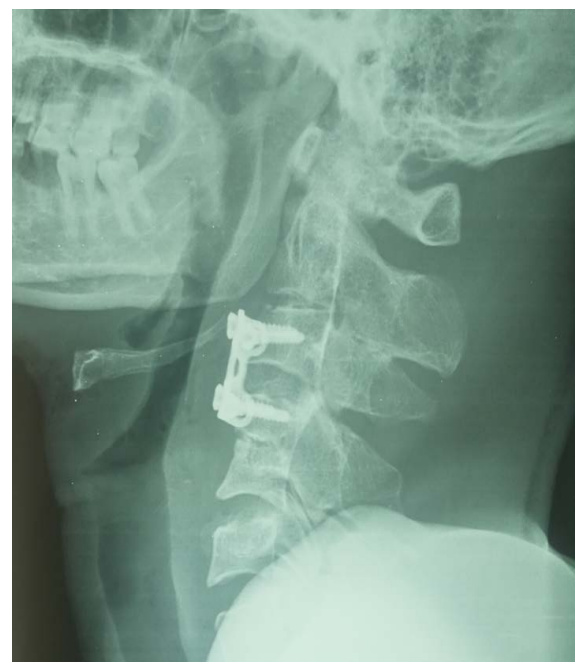

Figure 2. Postoperative lateral radiograph of the patient showing C3-C4 interbody fusion and 4 screws plating.

The most common fused cervical levels in KFS are C2-C3 (71.0\%) followed by C5-C6 (67.7\%), C6-C7 (67.6\%), and C3-C4 (29.0\%), with the mean number of total fused segments ranging from 3.5 to 3.7 [14] [15]. Our patient had a fusion at the $\mathrm{C} 2-\mathrm{C} 3$ and the $\mathrm{C} 4-\mathrm{C} 5$ levels. In spinal fusion, a disturbance in the distribution of segmental forces occurs. The merger creates a leverage effect. The hypermobility of the segments adjacent to the fusion results in transfer and amplification of stresses causing worsening of the lesions in the event of even minimal trauma. S. Vaidyanathan [16] reported a 51 year male who developped an incomplete tetraplegia when he slipped and fell backward hitting his head on the floor. Strax and Baran [17] reported a 13 year old girl whith KFS who became tetraplegic by falling of bed trying to shut off her alarm clock. Our patient became tetraparetic after slipping and falling from his height on the floor, this emphasizes the fact that persons with KFS are at risk for neurologic injury after a minor trauma.

Plain radiography and CT scan are the basis for the diagnosis of Klippel-Feil syndrome. CT scan provides optimal imaging of complex bony abnormalities and can be useful in surgical planning [18]. MRI is indicated in patients with neurologic deficits. MRI is the imaging modality of choice for evaluation of spinal cord abnormalities. It allows for assessment of soft tissue and provides contrast between the spinal cord and its surrounding structures. In patients with neurologic deficits, MRI of the entire spine should be done to search for central nervous system anomalies, such as a syringomyelia. In our context, the inaccessibility to MRI is mainly linked to its high cost and, moreover, this radiological exploration is not available in the region of Thiès. Patients are transported to Dakar in medical ambulance for a MRI assessment of lesions and then come back to Thiès.

Therapeutic options depend on the severity of symptomatic segmental instability or neurological compromise, varying from modification of activities to ex- 
tensive spinal surgery [19]. Technological advances have made more options available for surgical intervention in spinal disorders. From spinal fusion to artificial disc implantation, these advancements have brought great benefits, allowing preservation of spinal motion and flexibility after intervertebral discectomy [20]. A disc prosthesis is the best alternative to arthrodesis, especially since this, in addition to congenital fusion, accentuates the biomechanical disturbances of the cervical spine and exposes the adjacent segments to early degeneration [21] [22] [23] [24]. However, the decision to perform an arthrodesis or arthroplasty is difficult, as the natural history of KFS is poorly understood. Yi et al. [25] and Leung et al. [20] performed a one level arthroplasty at the C6-C7 and C4-C5 level, respectivelly and good results were encountered. ID Papanastassiou et al. [26] reported an arthroplasty failure 5 months postoperatively, in a 36-year-old woman with KFS who underwent two-level arthroplasty. Although motion preservation is desirable in Klippel-Feil patients, the biomechanics of their cervical spine may hinder arthroplasty and each case should be individualised. A Agrawal et al. [27] reported a 40-year-old KFS patient presenting complaints of weakness, tingling and numbness in all four limbs following fall from bicycle. The patient underwent a right anterior cervical approach, C4-C5 discectomy, fusion with autologus bone graft and C4-C5 fixation with a titanium plate and screws. Our patient underwent an anterior cervical discectomy and fusion with a four screws anterior plating. An ACDF was our only option because of high cost of a disc arthroplasty.

We believe that the earlier the decompression, the better it is. However, in our context, the timing of surgical intervention was delayed by practical constraints. A long admission delay due to the failure of the emergency management system, patients financially limited forradiological assessment and acquisition of osteosynthesis implants, were among limiting factors to do the surgery in a short time after admission.

Patients with KFS should be assessed for abnormalities besides cervical fusion such as Sprengel's deformity, congenital scoliosis, urinary tract malformations, cardiovascular abnormalities and others. There is high incidence of congenital anomalies of the genito-urinary tract in patients with KFS. In his study, WB Moore et al. [28], 25 of 39 patients with Klippel-Feil syndrome (64\%) had significant genitourinary-tract anomalies. The discovery of one anomaly should, therefore, stimulate a careful search for associated anomalies [4] [29]. Our patient was not assessed for associated anomalies because he was financially limited.

According to Kirigia et al. [30], it is in Africa that we find the lowest percentages of public expenditure devoted to health and it is also there that the contributions of households, through direct payment, are the highest. In our case, the patient had to pay forblood tests, radiological examinations, medical treatment, pre-anesthetic consultation, osteosynthesis implants and in the post-operative, he paid for blood tests, X-ray, medical treatment and the hospital stay. To improve patient care, health insurance is a central element in reducing the vulnera- 
bility of populations and limiting iatrogenic poverty. Health insurance will facilitate access to healthcare, by reducing the proportion of direct payment for services [31].

\section{Conclusion}

Understanding of the cervical spine biomechanics of Klippel-Feil anomaly may allow an optimal management of patients. Patients with KFS should be warned of the increased risk of spinal cord injury after a low velocity trauma and they should make an informed choice of their occupation and leisure activities. Efforts should be made to reduce timing of surgical intervention by improving emergency regulation at a national level and developing a health insurance program accessible to low-income households.

\section{Informed Consent}

Informed consent was obtained from the patient for publication of this manuscript and any accompanying images.

\section{Conflicts of Interest}

The authors declare no conflicts of interest regarding the publication of this paper.

\section{References}

[1] Louw, J.A. and Albertse, H. (1987) Traumatic Quadriplegia after Minor Trauma in Klippel-Feil Syndrome. South African Medical Journal, 72, 889-890.

[2] Diop, A.A., Hossini, A., Mbaye, E. and Faye, M. (2010) Hernie discale cervicale post-traumatique associée à un syndrome de Klippel-Feil: A propos d'une observation. Dakar Medical, 55, 131-135.

[3] Ly-Ba, A., Sakho, Y., Ba, M.C., Badiane, S.B., Badiane, M., Gueye, E.M. and Gueye, M. (1997) Caudal Regression Syndrome Associated with Klippel-Feil Syndrome. Dakar Medical, 42, 152-155.

[4] Hensinger, R.N., Lang, J.E. and MacEwen, G.D. (1974) Klippel-Feil Syndrome. A Constellation of Associated Anomalies. The Journal of Bone \& Joint Surgery, 56, 1246-1253. https://doi.org/10.2106/00004623-197456060-00018

[5] Buonuomo, P.S., Macchiaiolo, M., Colafati, G.S., Rana, I., Tomà, P., Gonfiantini, M.V., et al. (2014) Persistent Neck Pain in a Girl: Klippel-Feil Syndrome. Arch Dis Child, 99, 290-291. https://doi.org/10.1136/archdischild-2013-305203

[6] Gunderson, C.H., Greenspan, R.H., Glaser, G.H. and Lubs, H.A. (1967) The Klippel-Feil Syndrome: Genetic and Clinical Reevaluation of Cervical Fusion. Medicine, 46, 491-512. https://doi.org/10.1097/00005792-196711000-00003

[7] Gray, S.W., Romaine, C.B. and Skandalakkis, J.E. (1964) Congenital Fusion of the Cervical Vertebrae. Surgery, Gynecology and Obstetrics, 118, 373-385.

[8] Elster, A.D. (1984) Quadriplegia after Minor Trauma in the Klippel-Feil Syndrome: A Case Report and Review of the Literature. The Journal of Bone \& Joint Surgery, 9 , 1473-1474. https://doi.org/10.2106/00004623-198466090-00026

[9] Fietti Jr., V.G. and Fielding, W. (1976) The Klippel-Feil Syndrome: Early Roentge- 
nographic Appearance and Progression of the Deformity. A Report of Two Cases.

The Journal of Bone \& Joint Surgery, 58, 891-892.

https://doi.org/10.2106/00004623-197658060-00030

[10] Millan, M.M.C. and Stauffe, E.S. (1991) Traumatic Instability in the Previously Fused Cervical Spine. Journal of Spinal Disorders, 4, 449-454.

https://doi.org/10.1097/00002517-199112000-00007

[11] Karasick, D., Schweitzer, M.E. and Vaccaro, A.R. (1998) The Traumatized Cervical Spine in Klippel-Feil Syndrome: Imaging Features. American Journal of Roentgenology, 170, 85-88. https://doi.org/10.2214/ajr.170.1.9423605

[12] Pledger, S.R. (2003) Cervical Spine Disease. Ortho Secrets, 55, 107-118.

[13] Gruber, J., Saleh, A., Bakhsh, W., Rubery, P.T. and Mesfin, A. (2018) The Prevalence of Klippel-Feil Syndrome: A Computed Tomography-Based Analysis of 2,917 Patients. Spine Deformity, 6, 448-453. https://doi.org/10.1016/j.jspd.2017.12.002

[14] Samartzis, D., Kalluri, P., Herman, J., Lubicky, J.P. and Shen, F.H. (2011) Cervical Scoliosis in the Klippel-Feil Patient. Spine, 36, E1501-E1508. https://doi.org/10.1097/BRS.0b013e31823145e4

[15] Samartzis, D., Herman, J., Lubickey, J.P. and Shen, F.H. (2006) Classification of Congenitally Fused Cervical Patterns in Klippel-Feil Patients: Epidemiology and Role in the Development of Cervical Spine-Related Symptoms. Spine, 31, E798-E804. https://doi.org/10.1097/01.brs.0000239222.36505.46

[16] Vaidyanathan, S., Hughes, P.L., Soni, B.M., Singh, G. and Sett, P. (2002) Klippel-Feil Syndrome-The Risk of Cervical Spinal Cord Injury: A Case Report. BMC Family Practice, 3, Article No. 6. https://doi.org/10.1186/1471-2296-3-6

[17] Strax, T.E. and Baran, E. (1975) Traumatic Quadriplegia Associated with Klippel-Feil Syndrome: Discussion and Case Reports. Archives of Physical Medicine and Rehabilitation, 56, 363-365.

[18] Laker, S.R. and Concannon, L.G. (2011) Radiologic Evaluation of the Neck: A Review of Radiography, Ultrasonography, Computed Tomography, Magnetic Resonance Imaging, and Other Imaging Modalities for Neck Pain. Physical Medicine and Rehabilitation Clinics of North America, 22, 411-428.

https://doi.org/10.1016/j.pmr.2011.03.010

[19] Tracy, M.R., Dormans, J.P. and Kusumi, K. (2004) Klippel-Feil Syndrome: Clinical Features and Current Understanding of Etiology. Clinical Orthopaedics and Related Research, 424, 183-190. https://doi.org/10.1097/01.blo.0000130267.49895.20

[20] Leung, C.H.S., Ma, W.K. and Poon, W.S. (2007) Bryan Artificial Cervical Disc Arthroplasty in a Patient with Klippel-Feil Syndrome. Hong Kong Medical Journal, 13, 399-402.

[21] Gornet, M.F., Lanman, T.H., Burkus, J.K., Dryer, R.F., McConnell, J.R., Hodges, S.D., et al. (2019) Two-Level Cervical Disc Arthroplasty versus Anterior Cervical Discectomy and Fusion: 10-Year Outcomes of a Prospective, Randomized Investigational Device Exemption Clinical Trial. Journal of Neurosurgery: Spine SPI, 31, 508-518. https://doi.org/10.3171/2019.4.SPINE19157

[22] Hilibrand, A.S. and Robbins, M. (2004) Adjacent Segment Degeneration and Adjacent Segment Disease: The Consequences of Spinal Fusion? The Spine Journal, 4, 190S-194S. https://doi.org/10.1016/j.spinee.2004.07.007

[23] Wu, T.K., Meng, Y., Liu, H., Hong, Y., Wang, B.Y., Rong, X., et al. (2018) Primary Cervical Disc Arthroplasty versus Cervical Disc Arthroplasty Adjacent to Previous Fusion. A Retrospective Study with 48 Months of Follow-Up. Medicine, 97, e11755. https://doi.org/10.1097/MD.0000000000011755 
[24] Ryu, R.C., Behrens, P.H., Burkert, B.A., Johnson, J.P. and Kim, T.T. (2020) Two-Level Cervical Disc Arthroplasty in Patients with Klippel-Feil Syndrome: A Case Report and Review of the Literature. Surgical Neurology International, 11, Article No. 322. https://doi.org/10.25259/SNI_587_2020

[25] Yi, S., Kim, S.H., Shin, H.C., Kim, K.N. and Yoon, D.H. (2007) Cervical Arthroplasty in a Patient with Klippel-Feil Syndrome. Acta Neurochirurgica, 149, 805-809. https://doi.org/10.1007/s00701-007-1115-7

[26] Papanastassiou, I.D., Baaj, A.A., Dakwar, E., Eleraky, M. and Vrionis, F.D. (2011) Failure of Cervical Arthroplasty in a Patient with Adjacent Segment Disease Associated with Klippel-Feil Syndrome. Indian Journal of Orthopaedics, 45, 174-177.

[27] Agrawal, A., Badve, A.M., Swarnkar, N. and Sarda, K. (2009) Disc Prolapse and Cord Contusion in a Case of Klippel-Feil Syndrome Following Minor Trauma. Indian Journal of Orthopaedics, 43, 210-212.

[28] Moore, W.B., Matthews, T.J. and Rabinowitz, R. (1975) Genitourinary Anomalies Associated with Klippel-Feil Syndrome. The Journal of Bone \& Joint Surgery, 57, 355-357. https://doi.org/10.2106/00004623-197557030-00013

[29] Smith, B.A. and Griffin, C. (1992) Klippel-Feil Syndrome. Annals of Emergency Medicine, 21, 876-879. https://doi.org/10.1016/S0196-0644(05)81038-8

[30] Kirigia, J.M., Preker, A., Carrin, G., Mwikisa, C. and Diarra-Nama, A.J. (2005) An Overview of Health Financing Patterns and the Way forward in the WHO African Region. East African Medical Journal, 83, S1-S28. https://doi.org/10.4314/eamj.v83i9.9492

[31] Dussault, G., Fournier, P. and Letourmy, A. (2006) L' Assurance maladie en Afrique francophone Améliorer l'accès aux soins et lutter contre la pauvreté. Banque Mondial, Washington DC. 